\title{
Smart Waste Management System using IOT
}

\author{
Tejashree Kadus ${ }^{1}$, Pawankumar Nirmal $^{2}$, Kartikee Kulkarni ${ }^{3}$ \\ Department of Mechanical Engineering \\ MIT Academy of Engineering, Pune \\ Savitribai Phule University
}

\begin{abstract}
The paper is based on the concept of Automation used in waste management system under the domain of Cleanliness and Hygiene. Dumping garbage onto the streets and in public areas is a common synopsis found in all developing countries and this mainly end up affecting the environment and creating several unhygienic conditions. In order to deal with these problems Smart netbin is an ideology put forward which is a combination of hardware and software technologies i.e. connecting Wi-Fi system to the normal dustbin in order to provide free internet facilities to the user for a particular period of time. The technology awards the user for keeping the surrounding clean and thus work hand in hand for the proper waste management in a locality. Smart netbin uses multiple technologies firstly the technology for measuring the amount of trash dumped secondly the movement of the waste and lastly sending necessary signals and connecting the user to the WiFi system. The proposed system will function on client server model, a cause that will assure clean environment, good health, and pollution free society.
\end{abstract}

Keywords: Loadcell, IOT, load sensing plate, Arduino, Wi-Fi, Internet.

\section{INTRODUCTION:}

The amount of waste produced everyday by the industries and the households is increasing at an appalling rate, and the major reason for this is soaring use of packaged items, textiles, paper, food, plastics, metals, glass etc, thus management of this refuse becomes a crucial part in our everyday life.in most of the developed countries there are many efficient techniques which are used for the proper management of this waste, but in some countries especially the developing ones the careless attitude of people towards maintaining clean surroundings, along with this many issues such as no stringent laws for using the biodegradable materials, no proper environ policies ,no laws for sustainable development are the seed for the fatal results of waste management. Due to the increasing waste, the public bins which are used for collecting this waste are overflowing, the locality is jumbled of trash, causing not only malodorous streets but also a negative impact on the health and environment.

Waste is a crucial issue, which needs to be addressed smartly. we segregate the waste at our homes for ease at processing and recycling. We observed trash vans come irregular to homes creating a despoliation of households. Due to this many civilians empty their overloaded dustbins in open spaces. This in turn increases environmental pollution

The waste is a great hassle for our health and the environment it has many effects which are dreadful. Trash is breeding ground for bacteria, insects, flies these flies are the same that roam around the eatable and drop the off springs. thus they increase the risk with food poisoning, typhoid, gastroentetritis, salmonella, the insects cause malaria dengue etc, beside these flies and insects other animals that prosper from the trash are the rats and the stray dogs spreading diseases
, the garbage also causes various respiratory diseases the toxic contaminates such as co2 methane, nitrous oxide beside health issues adversely affect the environment causing air pollution water pollution. Disposal of hazardous waste like the electronic items, plastics in water affect the aquatic life and indirectly the human beings. Overflowing garbage is also a public hassle and eyesore. Everyone wants to visit fresh clean cities. A malodorous city with trash all around the place does not attract tourist thus loosing the money revenue and the opportunities.

As prosperity grows, 62 million tons of garbage is generated everyday by the 377 million people living in urban India, now the world's third largest garbage generator. However, it's not the amount of waste generated that's as much of an issue as the fact that more than 45 million tons, or 3 million trucks worth, of garbage is untreated and disposed of by municipal authorities every day in an unhygienic manner.

It is very salient issue to deal and discover the proper remedies for it some of them are like government should enact stringent laws against the people throwing trash, against the industries for not using biodegradable material, more use of recycle items, reduce the use of non-degradable stuff, reuse the items, thus implementing this can reduce the waste up to some extent. Along with this use of technology for proper dumping of trash and diminishing its hazardous effects is the concept put forward.

The internet nowadays has the world under its spell. Not a single person lives without internet, phone, tab or laptop. It is believed without connectivity u cannot move ahead in today's world but sometimes due to heavy plans or connectivity issues we can't access to the internet, and thus attracting people towards free $\mathrm{Wi}-\mathrm{Fi}$. providing free $\mathrm{Wi}-\mathrm{Fi}$ facility for dumping waste into the dustbin would solve the issue of waste and the internet facility plus availability of free service would help people go crazy and would act as reward for maintain cleanliness in the locality

\section{LITERATURE SURVEY:}

This is not an original idea, IOT based dustbin was implemented and effectuated much before. Some authors presented systems where the sensors in the bin checked if the bin are filled up to the brim or not. If it was filled an automated message was sent to the server end of the system, through the Arduino SIM module, which used the application of the Arduino board. Once the server received the message it forwarded the message to the worker in charge, if the worker was available, he would notify his/her presence by accepting the work and would reach the required destination. If the worker was not available, the work would be transferred to another worker.

Some authors also implemented real time waste management system by using smart dustbins to check the filled level of dustbins whether they were filled. In this system the 
information of all smart dustbins can be accessed from anywhere and anytime by the concern person and he/she can take a decision accordingly. By implementing this proposed system, the cost reduction, resource optimization, effective usage of smart dustbins was carried out. This system indirectly reduced traffic in the city. In major cities the garbage collection vehicle visited the area's everyday twice or thrice depending on the population of the particular area. The System informed the status of each and every dust bin in real time so that the concerned authority can send the garbage collection vehicle only when the dustbin is full.

Some proposed smart garbage management system using IR sensor, microcontroller and Wi-Fi module. This system assured the cleaning of dustbins soon when the garbage level reached its maximum. If the dustbin was not cleaned in specific time, then the records were sent to the higher authority who took appropriate action against the concerned contractor. This system also helped to monitor the fake reports and hence helped to reduce the corruption in the overall management system. It ultimately helped to keep cleanliness in the society

Progressively the Dustbin with Wi-Fi Router attached in it was also introduced. The Dustbin had a Passive Infrared Sensor. The Wi-Fi router was programmed to display the temporary connecting code. When the user throwed trash in the dustbin, the PIR sensor detected the trash and sent signals to the microcontroller. The microcontroller detected the signals and forwarded it to the router device. The router verified the signals and generated random codes and then forwarded it again to the microcontroller. The microcontroller scanned the signals and forwarded it to the LCD Display. The LCD Display displayed it. The user entered the random code generated by the router on the PHP interface which was hosted on the server. The server then responded to the request and displayed the Master Wi-Fi password to the user. The user then used the Master Wi-Fi password to connect to the internet. The user got the internet access for 10 minutes and automatically got disconnected.

\section{FLAWS IN THE EXISTING SYSTEM:}

The main problems of the existing solid waste collection process and management system are as follows:

- $\quad$ More complications in the processing.

- $\quad$ many controlling units linked with each other

- $\quad$ higher implementation cost

\section{PROPOSED SYSTEM:}

Smart netbin a normal dustbin elevated using a microcontrollerbased platform Arduino Uno board interfaced with Load sensor and Wi-Fi module.it consists of 2 main modules the mechanical designed components and the electric components. The mechanical components consist of shredder and the load sensing plate while the electric components consist of various components that are the Arduino

Loadcell, LCD Display screen, IR Sensor, Amplifier, Relay module, Wi-Fi Router.

When the user dumps the trash into the dustbin the trash will be first crashed within the shredder and the shredded trash will the get collected onto the load sensing plate present in the dustbin. The load sensor us been attached to the load sensing plate this sensor will measure the weight of the trash been dumped in the bin. once the set limit of weight is been satisfied the password of the router will get displayed on the LCD screen, although the router is still off .after the password has been displayed the user have to pull this plate outside so that the trash which has been collected on the plate falls down in the dustbin. This motion of the falling trash is captured by the IR sensor and once the IR sensor sense the falling motion

Advantages of proposed system over the existing:

- Low implementation cost

- Simple module

- Easy functionality
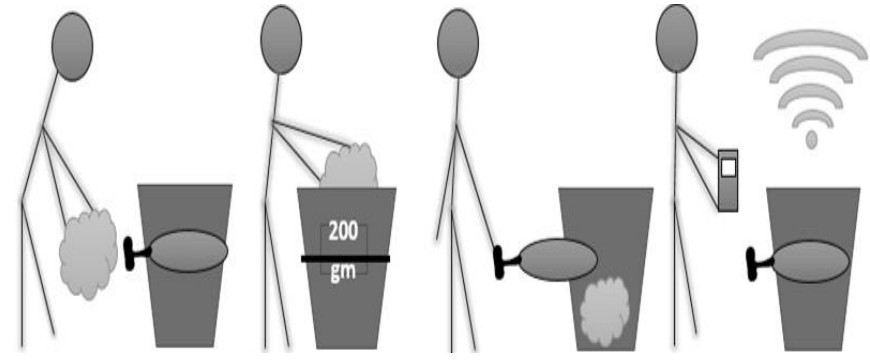

Fig.1: Proposed System.

\section{SYSTEM ARCHITECTURE:}

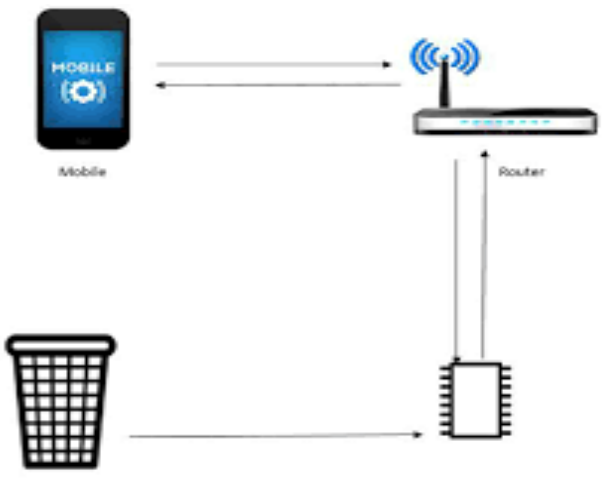

Fig.2: System Architecture

A. The system is composed of following components:

\section{The dustbin:}

A normal dustbin made of plastic or metal which can hold up all the components installed in it the mechanical shredder installed on the top side and the load sensing plate at the mediocre level all the IOT components will be installed at the bottom side. Thus, it should be of average size (height_600-700 mm dia_)

\section{Sensors:}

The sensing unit will mainly consist of 2 sensors i.e. the load sensor and the IR sensor the load sensor used for measuring the weight of trash being dumped into the dustbin and this is attached to the bottom side of load sensing plate, the IR sensor will detect the downward motion of trash once the load sensing plate s pulled out and the trash falls down in the bin 


\section{Load cell:}

During a measurement, weight acts on the load cell's metal spring element and causes elastic deformation. This strain (positive or negative) is converted into an electrical signal by a strain gauge ( $\mathrm{SG}$ ) that is installed on the spring element.

Product Name: Load Cell

Load: $10 \mathrm{Kg} / 22 \mathrm{lb}$

Rated Output: $1+/-0.15 \mathrm{mV} / \mathrm{V}$

Recommend Excitation Voltage: DC 5V; Max Excitation Voltage: DC 10V

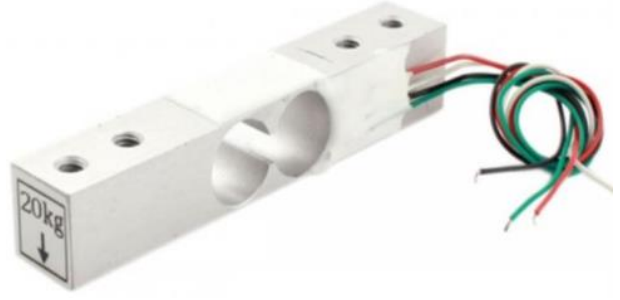

Fig.3: Load Sensor

\section{IR sensor:}

An infrared sensor is an electronic instrument that is used to sense certain characteristics of its surroundings. It does this by either emitting or detecting infrared radiation. Infrared sensors are also capable of measuring the heat being emitted by an object and detecting motion.

$\begin{array}{ll}\text { Operating Voltage Range } & 3.6 \sim 5 \mathrm{VDC} \\ \text { Average Current Consumption (mA) } & 0.06 \\ \text { Detection Angle } & 35 \hat{\mathrm{A}}^{\circ} \\ \text { Distance Measuring Range } & 2 \sim 30 \mathrm{~cm}\end{array}$

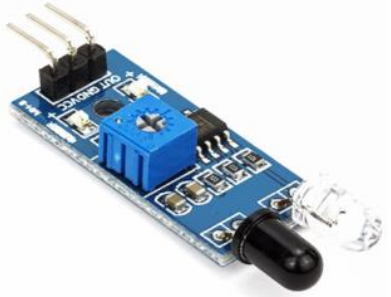

Fig.4: IR Sensor

\section{Wi-Fi module}

It consists of the router which will provide the internet facilities to the user for dumping the trash into the bin

6. Microcontroller:

Arduino will be the processing unit for the embedded system at the bins. This will be used for controlling sensors and send information.

The other components include:

\section{HX711 amplifier:}

Differential input voltage: $\pm 40 \mathrm{mV}$ (Full-scale differential input voltage is $\pm 40 \mathrm{mV}$ )

Operating Voltage: $2.7 \mathrm{~V}$ to $5 \mathrm{VDC}$

Operating current: $<10 \mathrm{~mA}$

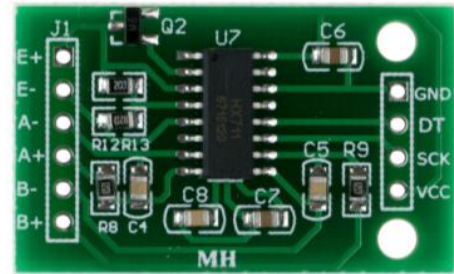

Fig.5: HX711 Amplifier

\section{LCD display:}

Operating Voltage is $4.7 \mathrm{~V}$ to $5.3 \mathrm{~V}$

$\square$ Current consumption is $1 \mathrm{~mA}$ without backlight

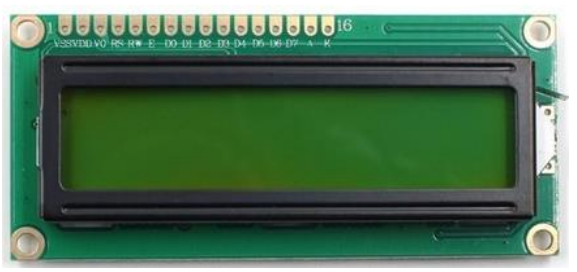

Fig.8: LCD Display (16*2)

\section{Power supply}

The Power supply will provide electrical power for the microcontroller, the shredder, and the router which are the most important part of the system.

\section{Shredder:}

A mechanical horizontal two shaft shredder is a machine used for reducing the size of all kind of material.it consist of shredding blade, loading box, box bracket, power system, the blade used is of steel. The specifications:

Voltage 200-300V

Power 4-15 kw

Capacity 80-800

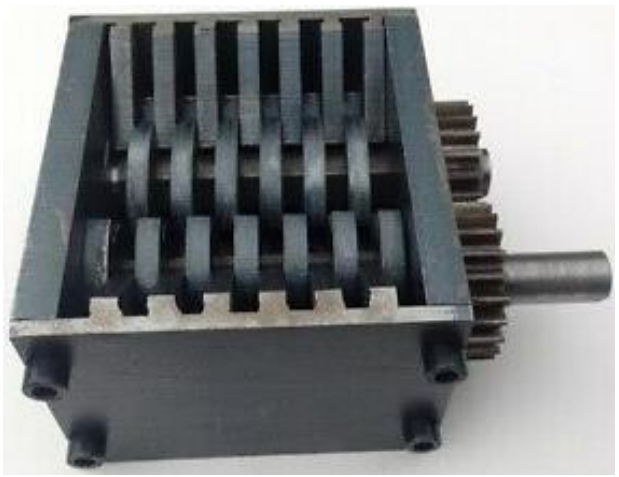

Fig.9: Mechanical Shredder.

\section{Load sensing plate}

The load sensing plate is a specifically designed plate according to the dustbin dimensions.it can be made of plastic wood metal it is used to collect the waste dumped into the bin and as the load sensor is attached to its bottom it measures the weight of the trash dumped in. it consist of holes so that the sand soil mud flows down through this holes and their weight is not been considered also the holes reduces the overall weight of the plate.it is installed at the $1 / 4^{\text {th }}$ height from the top of the dustbin 


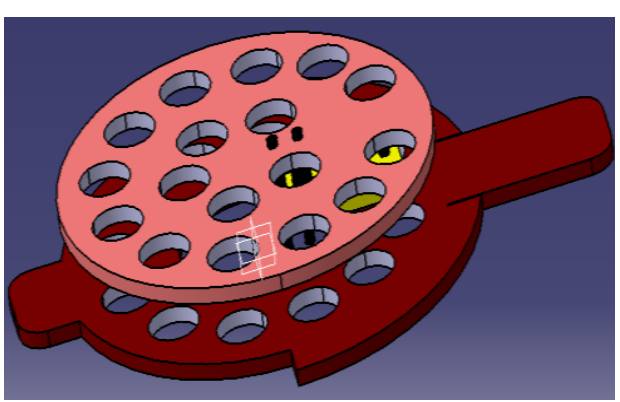

Fig.10: Load Sensing Plate.

\section{METHODOLOGY:}

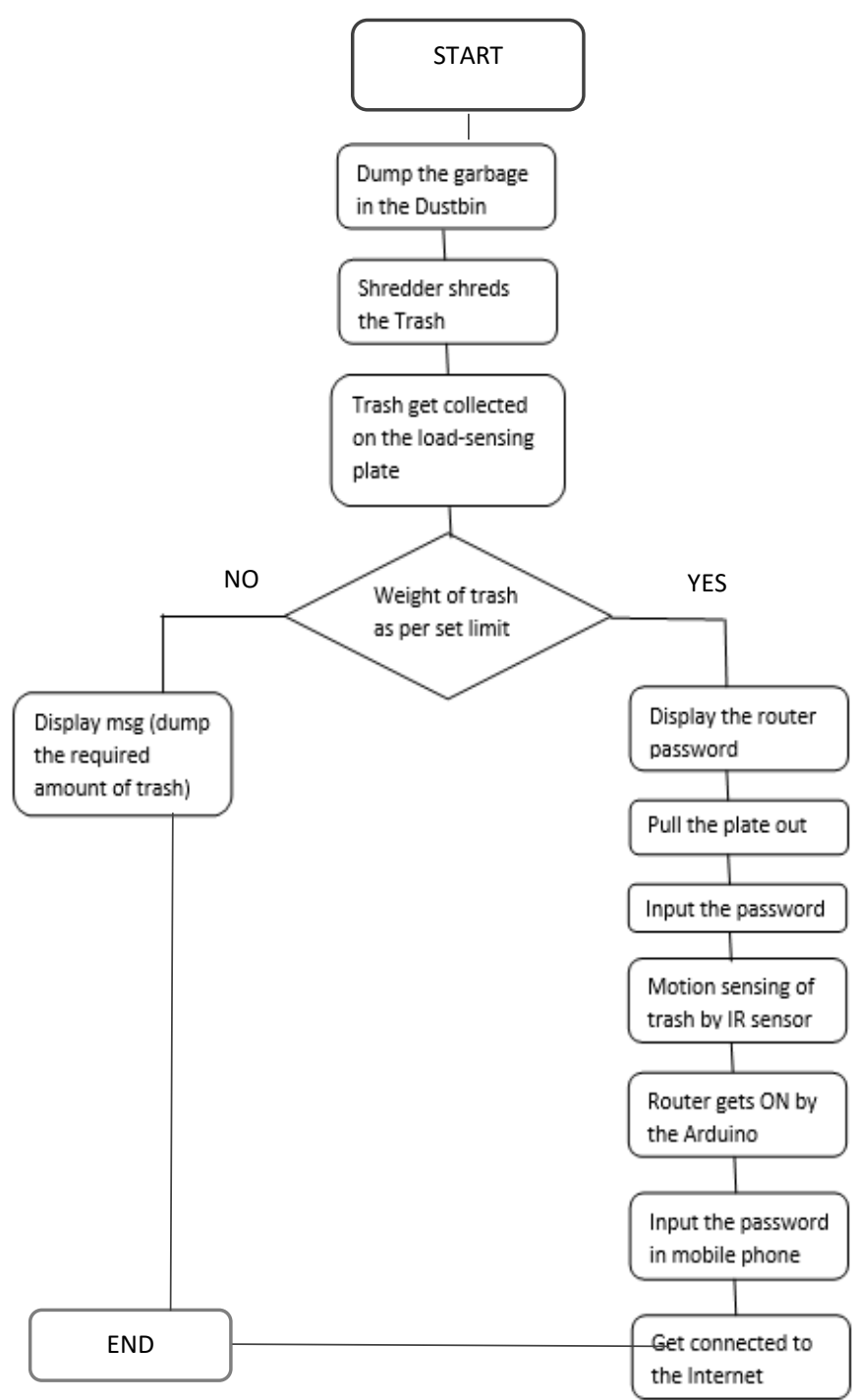

\section{ADVANTAGES:}

The proposed plan has many advantages, it is also cogent enough to be implemented in every street of a developing nation. the advantages lie in its easy and valuable functioning. This will not only improve the streets we live in, but also provide a pavement for better working system.

- Efficient and effective Functioning.

- Cleaner Environs

- Better health issues.

- Pollution free and stinking free environs
- Smart cities

- Technology development

- Tourist attraction.

Once implemented, this method would be easy to work on. The garbage will be dumped into the bins thereby reducing the health-threats imposed by the trash present all-around.

\section{FUTURE WORKS:}

The moisture sensor can be implemented hand in hand with the other sensors and the compartments for segregating the dry and wet waste can be created which will solve the issues related to waste segregation.

\section{CONCLUSION:}

Improper disposal and improper maintainance of domestic waste create issues in public health and environment pollution thus this paper attempts to provide practical solution towards managing the waste collaborating it with the use of IOT i.e. providing free internet facilities for a specific time once the trash is dumped into the bin. the proposed system will definitely help to overcome all the serious issues related to waste and keep the environment clean

\section{REFERENCES}

[1] P. Suresh, Vijay. Daniel, R.H. Aswathy, Dr. V. Parthasarathy, “A State-of-the-Art review on Internet of Things" International Conference on Science Engineering and Management Research (ICSEMR), IEEE, DOI: 10.1109/ICSEMR.2014.7043637 19 February 2015.

[2] Parkash, Prabu V "IoT Based Waste Management for Smart City" International Journal of Innovative Research in Computer and Communication Engineering, Vol. 4, Issue 2, DOI: 10.15680/IJIRCCE.2016. 0402029, February 2016.

[3] Evaluation on the Performance of Urban Domestic Sewage Treatment Plants in China - 2011 Dongmei Han; Guojun Song

[4] Teemu Nuortioa, Jari Kyto jokib, Harri Niskaa, Olli Bra ysyb "Improved route planning and scheduling of waste collection and transport", Expert Systems with Applications 30 (2006) 223-232, Elsevier

[5] M. Arebey, M. Hannan, H. Basri, and H. Abdullah, "Solid waste monitoring and management using RFID, GIS and GSM", The IEEE Student Conference on Research and Development (SCOReD), 16-18 November 2009, UPM Serdang, Malaysia, 2009

[6] M. Hannan, M. Arebey, R. A. Begum, and H. Basri, "Radio Frequency Identification (RFID) and communication technologies for solid waste bin and truck monitoring system", Waste Management, Vol. 31, pp. 2406-2413, 2011.

[7] S. Longhi, D. Marzioni, E. Alidori, G. Di Buo, M. Prist, M. Grisostomi, et al., "Solid Waste Management Architecture Using Wireless Sensor Network Technology", The 5th International Conference on New Technologies, Mobility and Security (NTMS), 7-10 May 2012, Istanbul, pp. 1-5, 2012. 147

[8] Waikhom Reshmi, RamKumar Sundaram, M. Rajeev Kumar, "Sensor Unit for Waste Management: A Better Method,", International conference on Science, Engineering and Management Research, (2014 IEEE 